\title{
Quebec left with numerous vacancies after resident match
}

$\mathrm{M}$ ore than $60 \%$ of the 126 vacancies left in all residency training programs after the second round of the 2009 Canadian Resident Matching Service were at the 3 Quebec francophone medical schools, an increase from $51 \%$ of the 121 vacancies in 2008 .

And family medicine vacancies at the 3 schools - Université Laval in Québec City, Université de Sherbrooke in Sherbrooke, and Université de Montréal in Montréal - accounted for $68 \%$ of the nation's .vacancies in that specialty (57 of 84), up from $61 \%$ in 2008 .

"We are really, really concerned" about the high number of family medicine residency positions left vacant, says Dr. Louise Authier, program director for family medicine at Université de Montréal.

The reasons for these high vacancy numbers are complex.

To Authier, a key reason is that although government policy led to an increase in available family medicine residency positions in Quebec this year, those positions were not promoted enough within medical schools.

Dr. Martin Bernier, president of the Fédération des Médecins Résidents du Québec, agreed there is a gap between policy and "the ability to fill spots. There is also the necessity to make family medicine interesting and attractive."

But Bernier also noted that Quebec suffered a net loss of 42 medical graduates from the province. To attract more graduates from outside and inside the province to residency positions, Quebec has to "set up conditions to make it attractive for people."

The cardiology resident at McGill University in Montréal says he meets medical residents from other provinces who "have heard about restrictions into practice and manpower allocation plans. ... Quebec has not built a good reputation for itself."

Nationally, there was a significant increase in the number of medical students choosing family medicine.

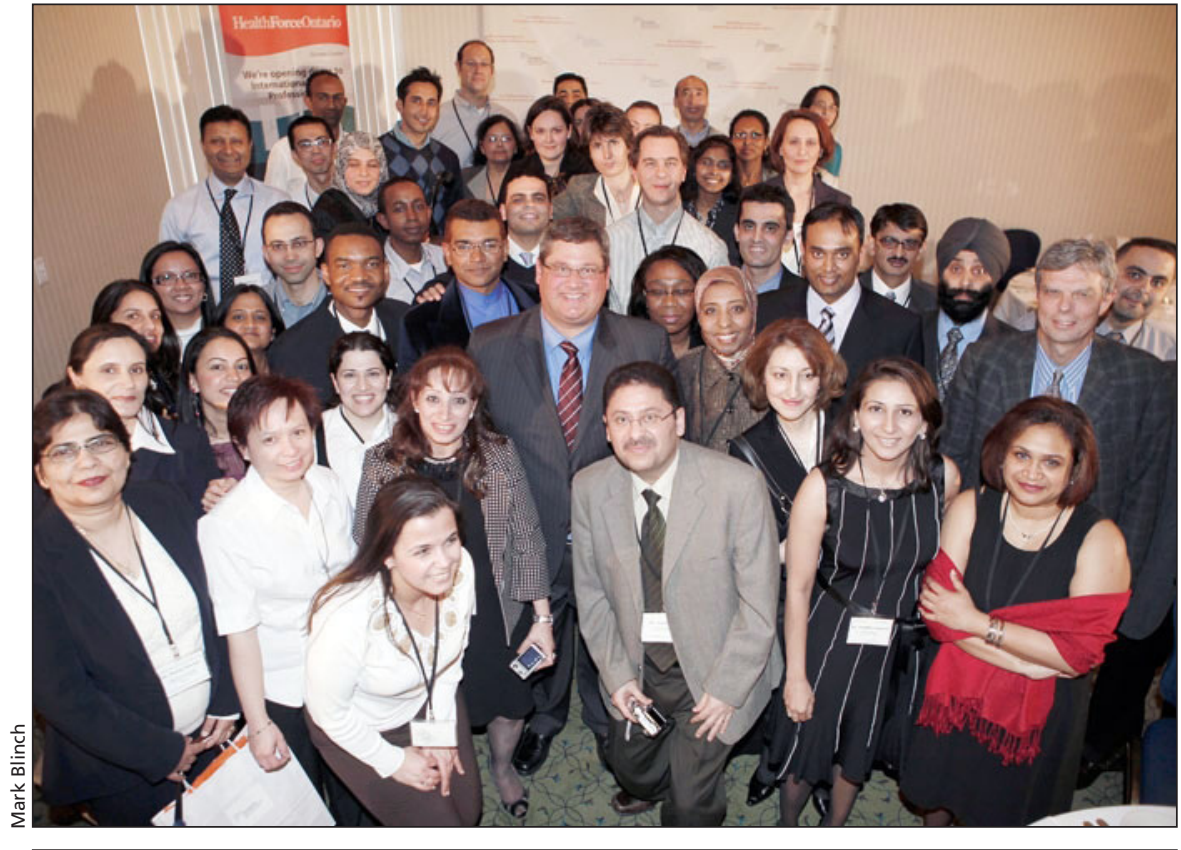

Roughly 50 international medical graduates who successfully found resident matches in the first iteration of the 2009 Canadian Resident Match Service selection process meet with Ontario Minister of Health and Long-Term Care David Caplan in late March.

\section{More international medical graduates placed}

A record 392 international medical graduates, up from the 2008 total of 353 , were matched into resident programs in Canada, according to second-round match results released last month by the Canadian Resident Matching Service.

Applicants from Europe and Central America/Caribbean were the most successful, with one-third from each group succeeding in landing a resident spot, while overall there was a success rate of $24 \%$ among the 1653 international graduate applicants.

There were 236 dedicated positions for the international graduates in the 2009 match, up from 219 a year earlier, though 11 remained unfilled after the second round, according to the match service report.

Ontario funded 200 of the dedicated spots, double the number from 2005, says Wayne Oake, a director with HealthForceOntario, a marketing and recruitment agency launched in 2007 that counts about 5000 international medical graduates among its 7000 clients.

Oake said he knows of 102 of his agency's clients who were matched after this year's second round of the matching service.

The clients receive counselling and support as they apply for medical residencies.

Alberta has its own program for international graduates, independent of the national service, and placed 55 such graduates in residencies, according to the national matching service. 
Of the 2313 Canadian graduates who participated in the match, 845 accepted family medicine residencies. "We are really thrilled at the steady increase in interest," says Paul Rainsberry, associate executive director, academic family medicine with the College of Family Physicians of Canada. "Family medicine is by far the largest intake and empty spots are not uncommon."

Roughly $86 \%$ of the first graduating class (30 of 35) at the Northern Ontario School of Medicine opted to accept family medicine residencies in the first round of the match. The next highest percentage of graduating classes accepting family practice residencies were Queen's University (46\%) in Kingston, Ontario, Université de Sherbrooke (45\%) and Université de Montréal (41.4\%).

As a result of the vacancies in family medicine in Quebec, sites that were opened in rural locations in expectation of increased resident numbers now find themselves short-staffed. "That is hard for the teachers, the patients, and local organizations," Authier says.

The match results show that a far greater proportion of graduates of the francophone medical schools, compared to other schools in Canada, stayed at the same university for residencies.

After family medicine, the residencies with the most vacancies after the second round of the match were internal medicine (all 13 vacancies at the Université Laval) and psychiatry, with a total of 6 vacancies at the universities of Sherbrooke, Montréal and Ottawa.

Dr. Roona Sinha, president of the Canadian Association of Interns and Residents, says there are "just so many factors" going into why some positions remain vacant, though she noted students from the rest of Canada may be less able to fill Quebec spots because of language difficulties.

The 3 Quebec francophone medical schools joined the national matching service in 2006. Before then, those schools did their own match after the national match ended. Still, prior to 2006 , individual medical graduates from the 3 universities were able to participate in the matching service, $\mathrm{Au}-$ thier said.

Meanwhile, Sinha is concerned that the residents' association was not consulted about a decision to place fourthyear internal medicine residents heading for subspecialities into a matching service like that used for first-year residents. The association recommends that a steering committee that includes residents and program directors be set up to monitor the process, says Sinha, a pediatric resident in Vancouver, British Columbia. — Ann Silversides, CMAJ

DOI:10.1503/cmaj.090977 